\title{
Socioeconomic position and health in a population of Brazilian elderly: the Bambuí Health and Aging Study (BHAS)
}

\author{
Maria Fernanda Lima-Costa, ${ }^{1}$ Sandhi M. Barreto, ${ }^{1}$ \\ Josélia O. A. Firmo, ${ }^{1}$ and Elizabeth Uchoa ${ }^{1}$
}

ABSTRACT Objective. Despite the vast scientific literature on the social determinants of health, there is still a debate on the extent to which this relationship remains in old age. The objective of this study was to examine the association between socioeconomic circumstances and health among older adults in a small town in Brazil.

Methods. The study was carried out in Bambui, a town of around 15000 inhabitants that is located in the state of Minas Gerais, which is in southeastern Brazil. From 1177 residents aged 65 years or older, 1074 of them (91.2\%) were interviewed and 997 (84.7\%) were examined (physical measurements and blood tests). Those in the lowest third of the distribution of total household monthly income, with an income of less than US\$240 per month, were compared with those who had an income above that level.

Results. Lower family income was independently associated with: (1) some lifestyle risk factors (less consumption of fresh fruits or vegetables and less frequent exercise during leisure time in the preceding 30 days), (2) several indicators of worse health status (General Health Questionnaire score, self-rated health, self-rated visual acuity, level of difficulty in walking 300 meters, inability to perform routine activities because of a health problem in the preceding 2 weeks, and seropositivity for Trypanosoma cruzi), (3) a higher number of nonprescribed medications used in the preceding 3 months, and (4) a higher number of hospitalizations in the preceding 12 months. Obesity was more frequent in the higher-income group.

Conclusions. The results of this study do not confirm observations in some developed countries of a lack of association between socioeconomic status and health among the aged. Our results showed that a small difference in monthly family income was sufficiently sensitive to identify elderly persons in worse health, even within a community that appears to be uniformly poor.

Key words Aged, health status, socioeconomic factors, health services accessibility, Brazil.

Despite the vast scientific literature on the social determinants of health,

\footnotetext{
1 Fundação Oswaldo Cruz and Universidade Federal de Minas Gerais, Núcleo de Estudos em Saúde Pública e Envelhecimento (NESPE), Belo Horizonte, Minas Gerais, Brazil. Send correspondence to: Maria Fernanda Lima-Costa, Núcleo de Estudos em Saúde Pública e Envelhecimento, Centro de Pesquisas René Rachou, Fundação Oswaldo Cruz, Av. Augusto de Lima 1715, 30190 002, Belo Horizonte, MG, Brazil; e-mail: lima-costa@cpqrr. fiocruz.br
}

few studies have examined socioeconomic circumstances and health among older individuals, and there is still a debate on the extent to which this relationship remains in old age (1). While some studies in developed countries have shown a positive association between better socioeconomic indicators and health (2-9), other studies have shown that the strength of this association is small or even disappears in older age (10-17). Three hypothesis are generally suggested to explain the lack of or weaker association between better socioeconomic indicators and health in the elderly: (1) disparities in income diminish after retirement, thus reducing existing differences in social and health indicators; (2) social policy aimed at reducing inequality among the elderly (such as the Medicare program in the United States of America) minimizes 
differences in access to quality care, with a reflection in health conditions; and (3) survival bias (premature mortality among lower-income people) and / or selection due to attrition (institutionalized individuals do not participate in population-based studies) (7).

Social inequalities have increased worldwide, especially in developing countries. Inequalities are particularly severe in the Region of the Americas, with Brazil, Guatemala, and Paraguay ranking respectively second, third, and fourth in the world in terms of income concentration (18). The older population is growing very rapidly in developing countries. Recent projections indicate that between 1990 and 2025 the population aged 60 and older will increase some seven to eight times in countries such as Colombia, Ghana, Kenya, Malaysia, and Thailand. Five of the 10 countries with the largest older populations in the world by 2025 will be developing countries. One of those 10 is Brazil, which will have some 27 million people over age 60 in 2025 (19). There is a growing concern regarding the rapid increase of the aged population in Brazil and other countries with great socioeconomic inequalities. However, the effects of socioeconomic circumstances on the health of the elderly in Brazil and in other developing countries have not been thoroughly investigated.

This article examines whether there is an association between socioeconomic position and health among older adults living in a small town in Brazil that appears to be uniformly poor. The study examined the influence of socioeconomic circumstances on biological, behavioral, and psychological risk factors; indicators of health status; and use of health services and medications.

\section{METHODOLOGY}

\section{Study area}

The subjects in this study were participants in the baseline portion of the Bambuí Health and Aging Study (BHAS). The BHAS is a population- based cohort study of older adults carried out in the town of Bambuí. The town of Bambuí is located in the municipality of the same name, in the state of Minas Gerais, which is in the southeastern part of Brazil (20).

The municipality of Bambuí has 20573 inhabitants, with 73\% of them living in the urban area of the municipality, that is, the town of Bambuí. In 1996, life expectancy was 70 years (21). The main causes of death were stroke, Chagas' disease, ischemic heart disease, and pulmonary chronic obstructive disease, with respective death rates of $110.0,61.4,42.5$, and 18.9 per 100 000. Bambuí was formerly an endemic area for Chagas' disease. Because the transmission of Trypanosoma cruzi was only interrupted around 20 years ago, the prevalence of infection among the aged remains high due to the cohort effect, and mortality from this cause is still high in the population.

The town has one general hospital, with 62 beds, and a public outpatient clinic that provides first aid services 24 hours a day. Some medications are distributed free by the local public health care system, but the system's stocks of medications are variable and erratic. In 1996 there was one doctor per 1000 inhabitants in the town. There is no institution for the elderly in the community (20).

\section{Study population}

Our team carried out a complete census in the town of Bambuí in November and December 1996 in order to identify participants for the cohort study. All residents aged 60 or older were selected for participation. Of 1742 residents in this age group, 1606 of them $(92.2 \%)$ were interviewed and 1496 (85.9\%) were examined (blood tests, anthropometric measurements, and blood pressure) in the baseline of the cohort study. Participants who were interviewed and who were examined were similar to the entire town population in this age group in all the characteristics investigated: age distribution, gender, number of persons in the household, conjugal status, family income, and education (20). All of the participants in the baseline study who were 65 or older were selected for this study. Interviews, physical measurements, and blood tests were performed between January and August 1997.

\section{Interview}

The following variables from the baseline BHAS interview were considered in this study: (1) sociodemographic characteristics (age, gender, and monthly family income); (2) social ties (contentment with social network, contentment with free-time arrangements (when not working), and presence of an informal caregiver at home for the elderly person when necessary); (3) lifestyle risk factors (smoking, consumption of fruits and/or vegetables, and physical activity during leisure time), (4) mental health (insomnia and psychiatric symptoms); (5) history of selected diseases (asked as, "Has a doctor ever said that you had angina pectoris, myocardial infarction, arthritis, or any other disease?"); (6) other measures of health status (self-rated health in the preceding 6 months, being unable to perform routine activities because of a health problem in the preceding 2 weeks, and staying in bed in the preceding 2 weeks because of any disease or chronic condition); (7) physical functioning (degree of difficulty in walking $300 \mathrm{~m}$; inability to perform at least one of the following activities of daily living: bathing, dressing, transferring from bed to chair, using the toilet, or eating; and visual acuity (asked as, "In general, do you think that your sightwith or without the help of glasses-is very good, good, bad, very bad, or blind?")); (8) use of health care services at public and/or private facilities (visits to a doctor in the preceding 12 months, and hospitalizations for at least one night in the preceding 12 months); (9) use of medications (number of prescribed medications and of nonprescribed medications used in the preceding 3 months); (10) source of health care (private care or public sys- 
tem); and (11) main complaint or dissatisfaction when seeking medical care or medication $(20,22)$.

Monthly family income, which is the dependent variable in this study, was assessed by asking respondents to indicate their total household income, from everyone living in the home, before taxes. We grouped the older persons into thirds, using multiples of the Brazilian minimum wage (BMW). (In 1997 the Brazilian minimum wage was US\$ 120 per month). The lowerincome group was defined as those in the lowest third, whose households were earning less than two BMWs (US\$ 240) per month.

Mental health was assessed in terms of two characteristics, insomnia and psychiatric symptoms. Insomnia was defined as a complaint, for the preceding 30 days, concerning difficulty in initiating sleep, frequency of disrupted sleep, or early morning awakening, happening three times a week or more, with any level of distress (23). To identify psychiatric symptoms (such as symptoms of depression and/or anxiety), we used the 12-item version of the General Health Questionnaire (GHQ), considering the symptoms that had occurred in the preceding 2 weeks (24). To define the presence of psychiatric symptoms, we used a cut-off score of $\geq 4$ on the GHQ. The GHQ version used in this study was previously validated in Brazil (25).

The interviews were carried out by individuals whom our team had selected from among community members with at least 11 years of schooling. When a respondent was unable to participate because of a cognitive deficit or for some other health reason, a proxy was used (such as another family member in the same household or the informal caregiver). Proxies were not asked questions that required personal judgment such as social ties, well-being, self-rated health, self-rated visual acuity, and mental health (20).

\section{Physical measurements}

Blood pressure was measured 30 or more min after the last caffeine intake or cigarette smoked, and after at least 5 min of initial rest. Three measurements were taken at 2-min intervals. The blood pressure level was considered to be the arithmetic mean of the second and third measurements $(20,22)$.

Anthropometric measurements were performed with individuals wearing light clothes and no shoes. As we lack population-based weight and height parameters for the elderly population of Brazil, underweight and obesity in this study were considered as the mean body mass index $(\mathrm{BMI}=$ weight $(\mathrm{kg}) /$ height $(\mathrm{m})$ squared) \pm one standard deviation. The respective cut-off values were 20 and $30 \mathrm{~kg} / \mathrm{m}^{2}$ (26).

\section{Blood tests}

Blood samples were drawn after recommended fasting for 12 hours. The following blood tests were considered in this study: glucose, total cholesterol, HDL cholesterol, triglyceride, and serology for Trypanosoma cruzi. Further details are described elsewhere $(20,21)$.

\section{Data analysis}

Data analysis was based on multiple logistic regression (27). Age and sex were a priori considered as confounding variables in the multivariate analysis. Proxy respondent was also considered as a confounding variable when the information was based on the BHAS interview (except for questions that required personal judgment: social ties, self-rated health, self-rated visual acuity, insomnia, and psychiatric symptoms). The analysis was carried out using the Stata statistical software (28).

\section{RESULTS}

From a total of 1177 residents aged 65 or older, 1074 of them $(91.2 \%)$ were interviewed and 997 (84.7\%) were examined (physical measurements and blood tests). Among the persons interviewed, $32.6 \%$ of them had a monthly family income of $<2.0$ Brazilian minimum wages (BMWs) (US\$240), 37.1\% had an income of 2.0-3.9 BMWs (US\$ 240 to US\$ 468), and $30.3 \%$ had an income $\geq 4.0$ BMWs (US\$ 480). (In presenting the results that follow, we compare the older residents whose households had an income of $<2.0$ BMWs (referred to as "lower income," "poorer," or "poor") with the residents whose households had an income of $\geq 2.0$ BMWs (referred to as "higher income" or "better off").

Lower monthly family income $(<2.0$ BMWs) was more frequent among the women than among the men $(67.0 \%$ and $58.2 \%$, respectively; odds ratio $(\mathrm{OR})=1.38 ; 95 \%$ confidence interval (CI): 1.10-1.72). Proxy respondents were used more frequently among those with a lower monthly family income in comparison with those who were financially better off $(9.2 \%$ and $5.8 \%$, respectively) (OR $=1.70 ; 95 \% \mathrm{CI}$ : 1.07-2.69). No significant associations were found between family income and age $(P>0.05)$.

Lower family income was associated with less consumption of fresh fruits or vegetables and with less frequent exercise. Obesity was more frequent among the better off (Table 1).

Current smoking, physical activity, systolic and diastolic blood pressure, blood glucose, total cholesterol, and HDL cholesterol were not significantly associated with monthly family income (all $P>0.05$ ). Level of fasting triglyceride was significantly associated with monthly family income in the crude analysis $(P=0.005)$, but this association disappeared after adjustments for age and sex.

No associations $(P>0.05)$ were found between family income and contentment with the social network or contentment with the free-time arrangements. The presence of a relative as an informal caregiver when necessary was less frequent among the poorer group $(83.2 \%)$ as compared with the higherincome group $(92.4 \%)$ (adjusted OR = 0.41; 95\% CI: 0.23-0.72).

Table 2 shows measures of health status significantly associated with monthly family income. A number of items were associated with lower 
TABLE 1. Behavioral and biological risk factors significantly associated with monthly family income among older adults, with adjusted odds ratio (OR) and 95\% confidence interval (Cl), Bambuí, Brazil, 1997

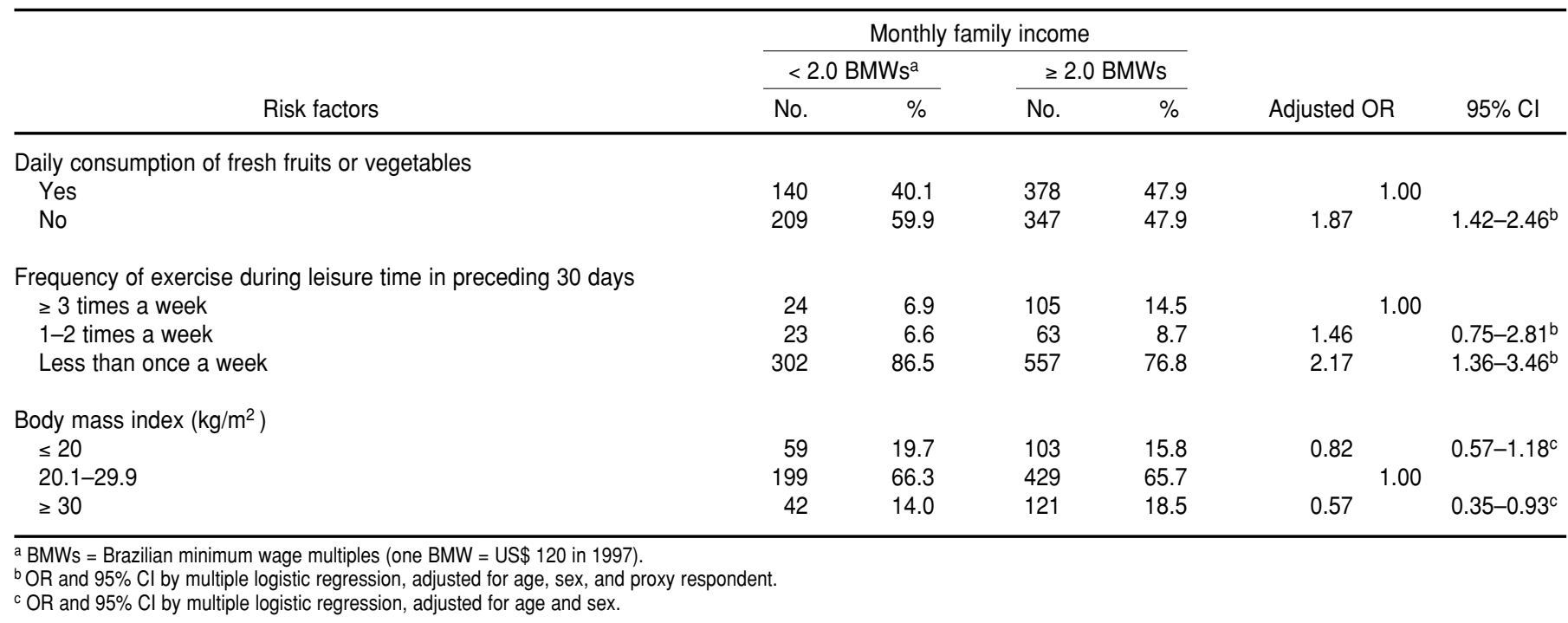

TABLE 2. Measures of health status significantly associated with monthly family income among older adults, with adjusted odds ratio (OR) and 95\% confidence interval (Cl), Bambuí, Brazil, 1997

\begin{tabular}{|c|c|c|c|c|c|c|}
\hline \multirow[b]{3}{*}{ Chronic diseases or health conditions } & \multicolumn{4}{|c|}{ Monthly family income } & \multirow[b]{3}{*}{ Adjusted OR } & \multirow[b]{3}{*}{$95 \% \mathrm{Cl}$} \\
\hline & \multicolumn{2}{|c|}{$<2.0 \mathrm{BMWs}^{\mathrm{a}}$} & \multicolumn{2}{|c|}{$\geq 2.0 \mathrm{BMWs}$} & & \\
\hline & No. & $\%$ & No. & $\%$ & & \\
\hline \multicolumn{7}{|l|}{ General Health Questionnaire score } \\
\hline$<4$ & 115 & 36.3 & 328 & 48.0 & & \\
\hline$\geq 4$ & 202 & 63.7 & 355 & 52.0 & 1.53 & $1.16-2.03^{b}$ \\
\hline Reasonable & 147 & 42.1 & 338 & 46.6 & 1.30 & $0.89-1.90^{\mathrm{b}}$ \\
\hline Bad/Very bad & 113 & 34.4 & 157 & 21.7 & 2.03 & $1.35-3.06^{b}$ \\
\hline \multicolumn{7}{|l|}{ Self-rated visual acuity } \\
\hline Very good & 5 & 1.4 & 23 & 3.2 & & \\
\hline Good & 157 & 45.2 & 372 & 51.3 & 2.05 & $0.76-5.51^{b}$ \\
\hline \multicolumn{7}{|l|}{ Degree of difficulty in walking $300 \mathrm{~m}$} \\
\hline Much/Unable & 105 & 30.4 & 159 & 22.0 & 1.47 & $1.10-2.05^{\mathrm{c}}$ \\
\hline \multicolumn{7}{|c|}{$\begin{array}{l}\text { Inability to perform routine activities because of a health problem } \\
\text { in preceding } 2 \text { weeks }\end{array}$} \\
\hline No & 217 & 77.6 & 626 & 86.3 & & \\
\hline Yes & 78 & 22.4 & 99 & 13.7 & 1.66 & $1.19-2.32^{c}$ \\
\hline \multicolumn{7}{|l|}{ Seropositivity for Trypanosoma cruzi } \\
\hline No & 155 & 49.5 & 437 & 65.1 & & \\
\hline Yes & 158 & 50.5 & 234 & 34.9 & 1.85 & $1.41-2.44^{b}$ \\
\hline
\end{tabular}


family income: GHQ score $\geq 4$, worse self-rated health, worse self-rated visual acuity, greater difficulty in walking $300 \mathrm{~m}$, inability to perform routine activities because of a health problem in the preceding 2 weeks, and seropositivity for T. cruzi. All these associations remained after adjustments for confounders.

Family income was significantly associated $(P<0.05)$ with insomnia in the preceding 30 days, inability to perform at least one of five activities of daily living, staying in bed in the preceding 2 weeks, and a previous medical diagnosis of arthritis in the crude analysis, but these associations disappeared after adjustments for confounding variables. A previous medical diagnosis of coronary heart disease or other chronic disease was not significantly associated with family income in the crude analysis $(P>0.05)$.

Those with a lower family income reported using a higher number of nonprescribed medications (two or more) during the preceding 3 months, having more hospitalizations (two or more) in the preceding 12 months, and using the public system as their source of health care (Table 3 ). The use of prescribed medications in the preceding 3 months and the number of visits to a doctor during this period were not significantly associated with socioeconomic circumstances $(P>0.05)$.

Older adults with a lower family income mentioned having more difficulties in paying for a medical visit, in making a medical appointment because of existing lines, and in obtaining medicines because of financial problems or any other problem (Table 4).

\section{DISCUSSION}

Our results demonstrate strong and independent associations between lower family income among the elderly and some biological and lifestyle risk factors, measures of health status, use of nonprescribed medications, and numbers of hospitalizations.

Other studies have also indicated that the poor elderly are less physically active, consume fewer fresh vegetables and fruits, and are more likely to have a poor diet (29-31). In contrast to developed countries (30), obesity in the older persons in our study was more common among those who were financially better off. The combination of obesity with better socioeconomic conditions has also been found in other developing countries. For exam- ple, in China and India, higher income levels, particularly in urban areas, were also associated with obesity and with consumption of a diet higher in fat $(30,32)$. Excess weight seems to appear first among the affluent and then among low-income groups. This pattern is likely due to a combination of reduced physical activity and a transition to a lipid-rich diet (33).

In comparison to the better-off elderly in Bambuí, the poorer elderly perceived their health as being worse, reported more psychiatric symptoms, had worse physical functioning, and had more difficulties in performing routine activities because of a health problem. With one exception, we did not find significant associations between poverty and specific diseases or specific chronic conditions in the study population. That exception was T. cruzi infection, which was more frequent among the poor aged. Taken together, the health attributes that we found to be associated with poverty suggest that the poor elderly have a lower quality of life. Physical functioning, psychiatric symptoms, and selfrated health are more salient indicators of quality of life than specific diseases. In addition, self-rated health and major depression have been found

TABLE 3. Indicators of use of health services and medications significantly associated with monthly family income among older adults, with adjusted odds ratio (OR) and 95\% confidence interval (Cl), Bambuí, Brazil, 1997

\begin{tabular}{|c|c|c|c|c|c|c|}
\hline \multirow[b]{3}{*}{ Characteristics } & \multicolumn{4}{|c|}{ Monthly family income } & \multirow[b]{3}{*}{ Adjusted OR } & \multirow[b]{3}{*}{$95 \% \mathrm{Cl}$} \\
\hline & \multicolumn{2}{|c|}{$<2.0 \mathrm{BMWs}^{\mathrm{a}}$} & \multicolumn{2}{|c|}{$\geq 2.0 \mathrm{BMWs}$} & & \\
\hline & No. & $\%$ & No. & $\%$ & & \\
\hline \multicolumn{7}{|c|}{ Use of nonprescribed medications during preceding 3 months } \\
\hline None & 275 & 79.9 & 608 & 84.3 & & \\
\hline 1 & 42 & 12.2 & 83 & 11.5 & 1.12 & $0.75-1.67^{b}$ \\
\hline $2+$ & 27 & 7.9 & 30 & 4.2 & 2.01 & $1.17-3.47^{b}$ \\
\hline \multicolumn{7}{|c|}{ Number of hospitalizations in preceding 12 months } \\
\hline None & 250 & 71.6 & 564 & 77.8 & & \\
\hline 1 & 59 & 16.9 & 122 & 16.8 & 1.01 & $0.71-1.43^{b}$ \\
\hline $2+$ & 40 & 11.5 & 39 & 5.4 & 2.11 & $1.31-3.39^{b}$ \\
\hline \multicolumn{7}{|l|}{ Source of health care } \\
\hline Public system & 315 & 90.5 & 557 & 76.8 & & \\
\hline Private & 33 & 9.5 & 168 & 23.2 & 0.36 & $0.24-0.55^{b}$ \\
\hline
\end{tabular}

a BMWs = Brazilian minimum wage multiples (one BMW = US\$120 in 1997).

${ }^{\mathrm{b}} \mathrm{OR}$ and $95 \% \mathrm{Cl}$ by multiple logistic regression, adjusted for age, sex, and proxy respondent. 
TABLE 4. Distribution of main dissatisfactions when seeking medical care or trying to obtain medication according to monthly family income, Bambuí, Brazil, 1997

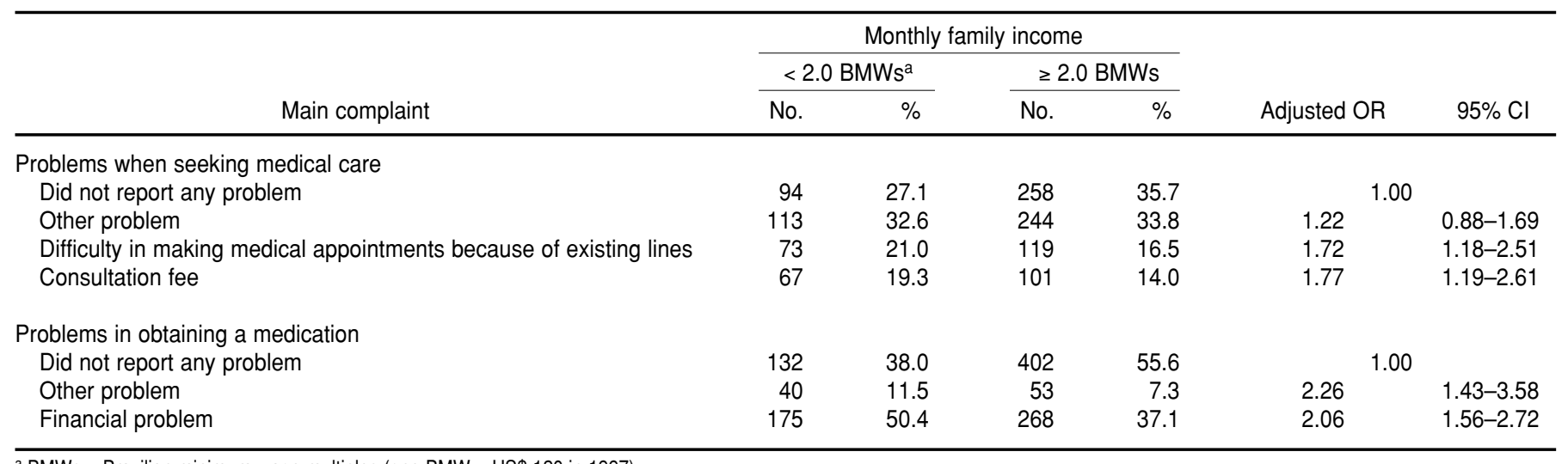

a BMWs = Brazilian minimum wage multiples (one BMW = US\$120 in 1997).

${ }^{b}$ Odds ratio and $95 \%$ confidence interval by multiple logistic regression, adjusted for age, sex, and proxy respondent.

to be consistent predictors of mortality among older adults $(34,35)$

It is possible that health in old age reflects the cumulative effect of a life of restricted health care (7), and there is some evidence that the poor aged are less likely to receive health care despite having adequate health insurance (36). In the Bambuí study, the poorer elderly reported more difficulties in using health services, even though access to health care is regarded as universal in Brazil. The poorer elderly also used more nonprescribed medications, were hospitalized more often, and reported more difficulties in arranging medical consultations and obtaining medications. On the other hand, no differences between poor and better-off elderly were found regarding the number of prescribed medications and the number of visits to a doctor.

As expected, the poor elderly mentioned financial problems more often as the main reason for difficulties in obtaining medications. An ethnographic study carried out in this community showed that in order to deal with this problem the poor elderly tend to adopt strategies that can have a negative effect on their health, such as purchasing only part of the prescribed medicines or reducing the dose of the prescribed medication (Uchoa E., personal communication, 2002).
We found that the poor elderly were hospitalized more frequently. This might be a consequence of worse health status, inadequate medical interventions, or a combination of those two factors. On the other hand, health status could not explain the frequency of visits to a doctor, which was similar among the poorer elderly and the better-off elderly in the study community. On the contrary, our results indicate that the poorer elderly have worse health status and, as a consequence, one could expect them to make more doctor's visits. Two of the problems in having access to medical care-the consultation fees and the long linesmight explain this apparently contradictory result.

While some studies have shown that lower-income groups have less social support $(37,38)$, another study has not shown that (6). In our study, contentment with the social network and with the free-time arrangements was similar for the poorer and the better-off elderly. However, having a relative as an informal caregiver was less frequent among the poorer elderly.

Regarding methodological aspects, several steps were followed to avoid bias in this study: collecting information using double-blinding, assessing the reliability of the data gathered, standardizing procedures and instruments, training of field-work and labo- ratory teams, and adjusting for several confounding variables. Internal validity was assured because the elderly participants in the baseline of the Bambuí cohort study were similar to the town's entire population of aged persons in terms of several sociodemographic characteristics (20). On the other hand, given that this is a crosssectional study, it is not possible to disentangle the temporal relations between economic hardship and health status or related conditions. But it is important to note that previous studies elsewhere have shown no evidence of reverse causation, that is, that episodes of illness might have caused subsequent economic hardship $(6,14)$. We used monthly family income as the measure of economic hardship in this study, instead of household income per capita, because total family income takes into account the economies of scale in household consumption, such as the costs of having a refrigerator and lighting, which are somewhat the same regardless of the number of persons in the household. In addition, studies have shown that the relationship between income inequality and mortality rates was virtually unchanged when results were simultaneously adjusted for taxes, transfer payments, and household size (39). We also preferred to use income (a characteristic that can change during the life- 
course) instead of schooling (a characteristic that in general does not change after a certain age) as an indicator of socioeconomic status because we were interested in the influence of the present economic circumstances on the health of the aged.

Our findings are based on a population of aged men and women in one small community in Brazil, but we believe that these results also apply to other similar communities in the country. The population of Bambuí is similar to the Brazilian population in various sociodemographic characteristics and health outcomes (mortality and hospitalizations), except for Chagas' disease $(20,21)$. This is true both for the entire population of Bambuí and for just the older persons in the community.

The results of this study do not confirm the observations in some developed countries of a lack of association between socioeconomic status and health among the aged. Our results showed that a small difference in monthly family income was sufficiently sensitive to identify elderly in worse health condition, even within a community that appears to be uniformly poor.

Acknowledgments. This study was sponsored by the Supporting Agency of Studies and Projects (FINEP), Brazil. The Brazilian National Research Council $(\mathrm{CNPq})$ provided scholarships to M.F. Lima-Costa, E. Uchoa, and S.M. Barreto. This study would not have been possible without the help of the people of Bambuí.

\section{REFERENCES}

1. Jefferys M. Social inequalities in health-do they diminish with age? [editorial]. Am J Public Health 1996;86:474-475.

2. Maddox GL, Clark D.O. Trajectories of functional impairment in later life. J Health Soc Behav 1992;33:114-125.

3. Cariney J, Arnold R. Social class, health and aging: socioeconomic determinants of selfreported morbidity among noninstitutionalized elderly in Canada. Can J Public Health 1996;87:199-203.

4. Robert S, House JS. SES differentials in health by age and alternative indicators of SES. J Aging Health 1996;8(3):359-388.

5. Ross CE, Wu CL. Education, age, and the cumulative advantage in health. J Health Soc Behav 1996;37:104-120.

6. Lynch JW, Kaplan GA, Shema SJ. Cumulative impact of sustained economic hardship on physical, cognitive, psychological and social functioning. N Engl J Med 1997;337:18891895.

7. Berkman CS, Gurland BJ. The relationship among income, other socioeconomic indicators, and functional level in older persons. J Aging Health 1998;10:81-98.

8. Parker MG, Ahacic K, Thorslund M, Lundberg O. Socioeconomic status and health among elderly people in Sweden. Ann N Y Acad Sci 1999;896:383-385.

9. Liao Y, McGee DL, Kaufman JS, Cao G, Cooper RS. Socioeconomic status and morbidity in the last years of life. Am J Public Health 1999;89:569-572.

10. Santariano WA. Race, socioeconomic status, and health: a study of age differences in a depressed area. Am J Prev Med 1986;2:1-5.

11. Kaplan GA, Seeman TE, Cohen RD, Knudsen LP, Guralnik J. Mortality among the elderly in the Alameda County Study: behavioral and demographic risk factors. Am J Public Health 1987;77:307-312

12. Feldman JB, Markuc DM, Kleinman JC, Coroni-Huntley J. National trends in educational differentials in mortality. Am J Epidemiol 1989;129:919-933.
13. House JS, Kessler RC, Herzog AR, Mero RP, Kinney AM, Breslow MJ. Age, socioeconomic status and health. Milbank Q 1990;68:383-411.

14. House JS, Lepkowski JM, Kinney AM, Mero RP, Kessler RC, Herzog AR. The social stratification of aging and health. J Health Soc Behav 1994;35:213-234.

15. Sorlie PD, Backlund E, Keller JB. US mortality by economic, demographic, and social characteristics: the National Longitudinal Mortality Study. Am J Public Health 1995;85:949-956.

16. Elo IT, Preston SH. Educational differentials in mortality: United States, 1979-85. Soc Sci Med 1996;42:47-57.

17. Beckett M. Converging health inequalities in later life-an artifact of mortality selection. J Health Soc Behav 2000;41:106-119.

18. World Bank. World development report 1998/99. Washington, D.C.: World Bank; 1999.

19. World Health Organization. Population ageing: a public health challenge. Geneva: WHO; 1998. (Fact Sheet no.135).

20. Lima-Costa MFF, Uchoa E, Guerra HL, Firmo JAO, Vidigal PG, Barreto SM. The Bambuî Health and Ageing Study (BHAS): methodological approach and preliminary results of a population based cohort study of the elderly in Brazil. Rev Saude Publica 2000;34:126-135.

21. Lima-Costa MFF, Barreto SM, Guerra HL, Firmo JAO, Uchoa E, Vidigal PG. Ageing with Trypanosoma cruzi infection in a community where the transmission has been interrupted: the Bambuí Health and Ageing Study (BHAS). Int J Epidemiol 2001;30:887-893.

22. Lima-Costa MF, Barreto SM, Uchoa E, Firmo JOA, Vidigal PG, Guerra HL. The Bambuí Health and Aging Study (BHAS): prevalence of risk factors and use of preventive health care services. Rev Panam Salud Publica 2001; 9(4):219-227.

23. Rocha FL, Guerra HL, Lima e Costa MFF. Prevalence of insomnia and associated sociodemographic factors in a Brazilian community: the Bambuí Study. Sleep Medicine 2002; 3:121-126.
24. Goldberg DP, Hillier VF. A scaled version of the General Health Questionnaire. Psychol Med 1979;9:139-145.

25. Mari JJ, Williams P. A comparison of the validity of two psychiatric screening questionnaires (GHQ-12 and SRQ-20) in Brazil, using Relative Operating Characteristic (ROC) analysis. Psychol Med 1985;15:651-659.

26. Barreto SM, Passos VMA, Lima-Costa MFF. Malnutrition and obesity among elderly in a Brazilian community: the Bambuí Health and Ageing Study. Cad Saude Publica. Forthcoming 2003.

27. Hosmer DW, Lemenshow S. Applied logistic regression. New York: Johns Wiley and Sons; 1989.

28. Stata Corporation. Stata statistical software release 6.0 (computer program). Stata Corporation: College Station, Texas, United States; 1997.

29. Popkin BM, Keyou G, Zhai F, Guo X, Ma H, Zohoori N. The nutrition transition in China: a cross-sectional analysis. Eur J Clin Nutr 1993;47:333-346.

30. James WPT, Nelson M, Ralph A, Leather S. Socioeconomic determinants of health: the contribution of nutrition to inequalities in health. Br Med J 1997;314:1545-1549.

31. Atalah E, Benavides X, Avila L, Barahona S, Cárdenas R. Características alimentarias de adultos mayores de comunas pobres de la Región Metropolitana. Rev Med Chilena 1998; 126:489-496.

32. Mehta P, Shringarpure B. Diet nutrition and health profile of elderly population of urban Baroda. Indian J Public Health 2000;44:124128.

33. Delpeuch F, Maire B. Obésité et développement des pays du sud. Med Trop (Mars) 1997;57(4):380-388

34. Menec VH, Chipperfield JG, Perry RP. Selfperceptions of health: a prospective analysis of mortality, control, and health. J Gerontol B Psychol Sci Soc Sci 1999;54:P85-93.

35. Schulz R, Beach SR, Ives DG, Martire LM, Ariyo AA, Kop WJ. Association between de- 
pression and mortality in older adults: the Cardiovascular Health Study. Arch Intern Med 2000;160:1731-1732.

36. Gornick ME, Eggers PW, Reilly TW, Mentnech RM, Fitterman LK, Kucken LE, et al. Effects of race and income on mortality and use of services among Medicare beneficiaries. N Engl J Med 1996;335:791-799.
37. Turner RJ, Marino F. Social support and social structure: a descriptive epidemiology. J Health Soc Behav 1994;35:193-212.

38. Oakley A, Rajan L. Social class and social support: the same or different? Sociology 1991;25: 31-59.

39. Kawachi I. Income inequality and health. In: Berkman L, Kawachi I, eds. Social epidemiol- ogy. Oxford, United Kingdom: Oxford University Press; 2000. Pp. 76-94.

Manuscript received 11 June 2002. Revised version accepted for publication 19 March 2003.

RESUMEN Objetivos. A pesar de la abundante bibliografía científica existente sobre los determinantes sociales de la salud, aún se debate hasta qué punto esa relación se mantiene durante la edad avanzada. El objetivo de este trabajo fue examinar la asociación entre

Situación socioeconómica y salud en una población de adultos mayores brasileños: el Estudio de Salud y Envejecimiento de Bambuí la situación socioeconómica y la salud en adultos mayores de una pequeña localidad de Brasil.

Métodos. El estudio se llevó a cabo en Bambuí, una ciudad de alrededor de 15000 habitantes ubicada en el estado de Minas Gerais, en el sudeste brasileño. De los 1177 residentes de 65 años de edad o más, 1074 (91,2\%) fueron entrevistados y a $997(84,7 \%)$ se les realizaron mediciones antropométricas y análisis de sangre. Se comparó a las personas ubicadas en el tercio más bajo según la distribución de los ingresos mensuales totales de su núcleo familiar — con ingresos mensuales inferiores a US\$240,00con las que tenían ingresos superiores.

Resultados. Los ingresos familiares inferiores estuvieron asociados de manera independiente con: 1) algunos factores de riesgo en el estilo de vida (menos consumo de frutas o vegetales frescos y ejercicios menos frecuentes en el tiempo libre durante los 30 días previos a la entrevista), 2) peor estado de salud según varios indicadores (puntuación en el Cuestionario General de Salud, autovaloración del estado de salud y de la agudeza visual, grado de dificultad para caminar 300 metros, incapacidad para realizar las actividades cotidianas debido a problemas de salud en las 2 semanas previas y seropositividad a Trypanosoma cruzi), 3) uso de un mayor número de medicamentos no prescritos en los 3 meses anteriores, y 4) mayor número de hospitalizaciones en los 12 meses previos a la entrevista. La obesidad fue más frecuente entre las personas del grupo de mayores ingresos.

Conclusiones. Contrario a lo observado en algunos países desarrollados, se encontró correspondencia entre la situación socioeconómica y el estado de salud de los adultos mayores. Según nuestros resultados, pequeñas diferencias en los ingresos mensuales de una familia permiten identificar a personas mayores en peor estado de salud, aun dentro de una comunidad que parece tener un nivel uniforme de pobreza. 